\title{
Gastric Cancers in Texas: Are Nitrates the Problem?
}

Author: Steve Mlinarich

Faculty Mentor: Joseph Oppong, Department of Geography, College of Arts and Sciences

Department and College Affiliation: Department of Geography, College of Arts and Sciences 


\section{Biography:}

Steve Mlinarich is a 2008 graduate of the University of North Texas with a Bachelors of Arts in Geography. His undergraduate coursework included study in Medical Geography, Soil Geomorphology, Groundwater Hydrology, Geographic Information Systems, and Remote Sensing. His research was presented at the 2008 Annual Meeting of the Association of American Geographers in Boston, Massachusetts, as well as University Scholar's Day at the University of North Texas. Steve is currently a Geographic Information Systems (GIS) Technician for an oil and natural gas company in Fort Worth, Texas. His future plans include attending graduate school in order to continue research in the field of Medical Geography. 


\begin{abstract}
:
Although in recent years the prevalence of gastric cancers such as stomach and esophageal have dwindled slightly due to changes in diet, gastric cancers remain the second leading cause of cancer death worldwide. Past studies have shown a positive relationship between gastric cancers and increased intake of nitrites and nitrates. This study examines the geography of gastric cancer mortality in Texas counties in relation to the median nitrate concentration of groundwater wells. In addition, the correlations of gastric cancer mortality and race/ethnicity, gender, socioeconomic status, rural-urban residence, and employment in agriculture and mining are also explored. Whereas no correlation was found between median nitrate concentration levels and gastric cancer mortality, significant correlations were found with percent Hispanic population, percent urban, and percent White population. The study shows that in Texas, the relationship between nitrates and gastric cancer may not be as significant a factor as reported elsewhere.
\end{abstract}




\section{Introduction}

Gastric cancer remains the $14^{\text {th }}$ most common cancer in the United States despite a drastically reduced incidence since the 1930s (Gastric Cancer Facts, n.d.). However, on a global scale, gastric cancers are the second leading cause of cancer death (Roder, 2002). Adenocarcinoma, which accounts for 90 percent to 95 percent of all gastric cancers, first develops in the lining of the stomach walls. Some of the major links with gastric cancer include Helicobacter pylori gastric infection; diets low in fruits and vegetables; diets high in salted, smoked, or preserved foods; and environmental factors (National Cancer Institute, n.d.). It is important to further study the spatial relationship among gastric cancer mortality, environmental, and socioeconomic factors to further decrease gastric cancer mortality in the United States and worldwide.

\section{Objective}

This paper examines the spatial relationship between gastric cancer mortality in Texas and nitrates by looking at the following variables: race/ethnicity, gender, and socioeconomic status (median income). Median nitrate concentrations in groundwater wells are examined as well as employment in agriculture and mining, two industries that use nitrates in large amounts as fertilizers and explosives. The paper begins with a brief literature review, followed by the research hypothesis, the results, and the conclusion and discussion.

\section{Methodology and Data Sources}

For this study, gastric cancer is defined as ICD-9 codes 150-151, and the data were obtained from the Texas State Department of Health Services. Gastric cancer mortality data have been age-adjusted to the 2000 U.S. Census standard to eliminate intercounty differences in age distribution. Data on nitrate concentration in groundwater wells were obtained from the Texas 
Water Development Board. Race/ethnicity, gender, industry type, and median household income are from the 2000 U.S. Census. Industry type was derived from the percentage of the working population that is involved in agriculture and mining industries.

\section{Literature Review}

Gastric cancers include stomach cancer, small intestine cancer, and esophageal cancer. Previous studies have shown a link between gastric cancers and occupations that involve exposure to nitrogen-based chemicals. Evidence of increased risk among coal miners is strong and a factor that links the two is that nitrogen oxides are common in explosives for underground mines. In addition, farmers have been observed to have a higher risk of gastric cancers due to the use of organic and inorganic dusts, pesticides, fertilizers, and diesel fuels. Exposure in farming can be from inhalation or handling during application processes (Roder, 2002). Anderson, Hógsaet, Langård, and Zandjani (1994) show an increased risk of gastric cancer among workers in nitrate fertilizer factories. Also, heavy fertilizer use increases the nitrate level in groundwater. Nitrate intake levels are higher in diet and drinking water than in occupational exposures (Roder, 2002). According to the Environmental Protection Agency (EPA), the Maximum Contaminant Level (MCL) for nitrates is $44.27 \mathrm{mg} / \mathrm{L}$. The short-term effect of high levels of nitrate in drinking water has caused serious illness and sometimes death. In the long term, nitrates and nitrites have the potential to cause diuresis, increased starchy deposits, and hemorrhaging of the spleen due to lifelong exposure to levels above the MCL. Primary sources of nitrates are livestock manure, human sewage, and fertilizers. Because nitrates are highly soluble and do not bind to soils, they have a propensity to migrate into the groundwater. Because they do not evaporate, they are left in the groundwater until consumed by plants or animals. The EPA's regulation of nitrates and nitrites did not take effect until 1992 (EPA, n.d.). Burbano, Correa, 
Cuello, Duque, and Garcia (1976) also found a positive relationship between gastric cancer and nitrate content of well water. Because nitrate is endogenously reduced to nitrite and subsequent nitrosation reactions give rise to $\mathrm{N}$-nitroso, which is highly carcinogenic and acts systemically, drinking water with a high level of nitrate may increase cancer risk (Cerhan, Hallberg, Kross, \& Weyer, 2001). Similarly, Cheng, Hsieh, Tsai, and Yang (1998) show a positive association between drinking water's exposure to nitrates and gastric cancer. Although nitrate intake can be associated with increased risk of gastric cancers, other factors such as age, gender, diet, blood type, and h. pylori are important. Most cases are diagnosed in patients in their mid-50s, with women having a lower risk than men. Those with type A blood and diets low in fruits and vegetables and high in salted, smoked, and preserved foods have a higher risk, while Helicobacter pylori are linked to gastric ulcers and chronic atrophic gastritis (Harvard Center for Cancer Prevention, n.d.). In addition, race and ethnicity factors into the incidence and mortality due to gastric cancers. Hispanics are found to have the greatest rates of gastric cancers, followed by Blacks, then Whites (Jemal, Siegel, Ward, Murray, Xu, Smigal, \& Thun, 2006). Another factor that is associated with cancer risk is that of living in a rural or urban environment. Doll (2006) states urban areas have higher incidence and mortality due to cancer than rural areas; it is also noted that gastric cancer incidence increases as socioeconomic status decreases (Gastric Cancer Facts, n.d.). However, there are ways to reduce the risk of developing stomach cancer, such as increasing daily intake of fruits and vegetables. Numerous potentially anticarcinogenic agents are found in fruits and vegetables, including carotenoids, vitamins $\mathrm{C}$ and $\mathrm{E}$, selenium, dietary fiber, dithiolthiones, glucosinolates and indoles, isothiocyanates, flavonoids, phenols, protease inhibitors, plant sterols, allium compounds, and limonene. These agents have both complementary and overlapping mechanisms of action, including the induction of detoxification 
enzymes, inhibition of nitrosamine formation, provision of substrate for formation of antineoplastic agents, dilution and binding of carcinogens in the digestive tract, alteration of hormone metabolism, and antioxidant effects (Potter \& Steinmetz, 1991).

Hypotheses

Six main hypotheses are tested in this research:

Hypothesis 1 . Hispanics have a higher rate of gastric cancer mortality than Blacks or Whites.

Hypothesis 2. Males have higher gastric cancer mortality rates than females.

Hypothesis 3. Counties with lower socioeconomic status have higher rates of gastric cancer mortality.

Hypothesis 4. Counties with large agricultural and mining industries have higher rates of gastric cancer mortality.

Hypothesis 5. Counties with large urban populations have higher rates of gastric cancer mortality than counties with large rural populations.

Hypothesis 6. Counties with high median nitrate concentration in groundwater wells have higher rates of gastric cancer mortality.

\section{Results}

Gastric cancer mortality is greater in the southern portion of the state along the Mexican border (Figure 1), along with some high rates along the Gulf Coast. Low mortality rates are observed in the eastern and northern areas of the state, with the lowest rates in the northwest Texas Panhandle and north central region. The mean age-adjusted death rate for gastric cancers is 8.5 per 100,000 across Texas.

Race/Ethnicity and Gastric Cancers 
The original hypothesis stated that Hispanics would have the greatest mortality due to gastric cancers, followed by Blacks, then Whites. When looking at gastric cancer on the county level for Texas, this hypothesis was confirmed. A significant negative correlation is present between the percentage of the White population and gastric cancer mortality rates with a Pearson correlation of -.354 . Figure 2 shows the percentage of the White population of each county across the state of Texas. This indicates that as the percentage of Whites increases, the mortality due to gastric cancers decreases. Also, the findings showed a significant positive relationship with the percentage of Hispanic population and mortality due to gastric cancers with a Pearson correlation of .296. In short, as the percentage of the White population in a county increases, mortality due to gastric cancers decreases. In contrast, as the percentage of the Hispanic population in a county increases, the mortality due to gastric cancers also increases. This would explain why higher mortality rates due to gastric cancer are found in the southern portion of Texas, near the Mexican border.

Figure 3 presents the percentage of Hispanic population across the state of Texas. The positive relationship between Hispanics and gastric cancer could be related to greater exposure to infectious agents and dietary patterns (O’Brien, Cokkunides, Jemal, Cardinez, Murray, Samuels, Ward, \& Thun, 2003). As far as Blacks are concerned, there was no significant relationship. However, when age-adjusted death rate for gastric cancer was examined at the statewide level, Blacks had the greatest rate at 18.2 per 100,000, followed by Hispanics and Whites with 11.6 and 7.5 , respectively. This could be explained in part by the fact that minority populations are generally more likely to be diagnosed with advanced stages of disease than Whites.

\section{Gender and Gastric Cancers}

It was hypothesized that males would have greater rates of gastric cancer mortality than 
females, as previous research suggested. This hypothesis was confirmed. The mean and median age-adjusted death rate due to gastric cancers for males was 12.6 per 100,000, as opposed to a mean rate of 5.3 and a median rate of 5.2 for women. Although biological factors could account for the difference, it could also be the fact that females are more likely to visit doctors earlier and more often than males. They are also more likely to lead a healthy lifestyle (Lonnquist \& Weiss, 2006).

\section{Socioeconomic Status and Gastric Cancers}

The measure of socioeconomic status used was median income. It was hypothesized that gastric cancer mortality would have a negative relationship with median income. However, there was no significant correlation found for the state as a whole. When looking at median income and race, there were some interesting findings. There was a significant positive correlation between the percentage of the White population of the county and the median income of the county, with a Pearson correlation of .377 . This suggests that as the percentage of the White population increases, so does median income. It was also found that there is a significant negative correlation between the percentage of the Hispanic population and median income, meaning that as the percentage of Hispanic population increases, the median income decreases. However, the correlation between the percentage of the county's Black population and median income was not significant. This is important because, although median income across the whole state shows no correlation with gastric cancer mortality, it appears that socioeconomic status and race play a role, because Hispanics have higher rates of gastric cancer mortality and lower median income, and Whites have lower rates of gastric cancer mortality and higher median income.

Agriculture, Mining, and Gastric Cancers 
The hypothesis was that areas of the state with a higher percentage of the population engaged in agriculture and mining industries would have higher gastric cancer mortality rates due to the use of nitrates as fertilizers in agriculture and explosives in mining. Figure 4 shows the percentage of the population engaged in agriculture across the state of Texas is concentrated mainly in the western and northwestern portion of the state. Figure 5 shows the percentage of the population of the county that is engaged in mining in the state of Texas, which is mainly concentrated in the western portion of the state below the Panhandle in the Permian Basin. However, there was no significant relationship between agriculture or mining and gastric cancer mortality.

\section{Urban, Rural, and Gastric Cancers}

It was hypothesized that there would be a positive relationship between the percentage of urban and gastric cancer mortality and a negative relationship between the percentage of rural and gastric cancer mortality. This hypothesis was because people living in urban areas tend to engage in different personal behaviors than those in rural areas. These include smoking, alcohol consumption, and dietary habits. Other differences are pollution and occupational hazards (Doll, 2006). This hypothesis was confirmed. There was a significant positive relationship between urban and gastric cancer mortality, meaning the more urban the area, the higher the gastric cancer mortality rate. Figure 6 shows the percentage of the county population living in urban areas across the state of Texas. It is also interesting to note here that there is a significant negative relationship between the percentage of that county that is White and the percentage living in urban areas, with a Pearson correlation of -.434 , which is significant at the 0.01 level. Also, there is a significant positive correlation between the percentage of Hispanics and urban dwellers with a Pearson correlation of .348, which is significant at the 0.01 level. This finding 
could explain the previously discussed relationships among Whites, Hispanics, and gastric cancers.

\section{Nitrates and Gastric Cancers}

The original hypothesis stated that areas with high nitrate concentration in groundwater wells would have high gastric cancer mortality. The research did not show a significant relationship between median nitrate concentration and gastric cancer mortality. This adds weight to the argument that nitrates are not significantly related to gastric cancers in Texas. However, it is interesting to note that there was a cluster found in the Permian Basin region with aboveaverage median nitrate concentration $(8.45 \mathrm{mg} / \mathrm{L})$ and above-average, age-adjusted gastric cancer mortality $(8.5$ per 100,000$)$. Also, a cluster of high nitrate concentration and high gastric cancer mortality was found in the southern tip of Texas, which has a higher percentage of at-risk industries, similar to the Permian Basin region. Figure 7 shows the clusters of high nitrate concentration and high gastric cancer mortality.

\section{Change through Time}

When mortality rates due to gastric cancers were examined across the span of 19 years, from 1980 through 1998, very little change was found. From 1980 to 1985 , the mean gastric cancer mortality rate was 8.4 per 100,000 and the median rate was 8.2 . From 1986 to 1991 , the mean gastric cancer mortality rate was 8.2 per 100,000 and the median rate was 8.1 . During the span of 1992 to 1998 , the mean gastric cancer mortality rate was 8.9 per 100,000 and median rate was 8.6. Between 1980 to 1985 and 1986 to 1991 , the mean change was a decrease of 0.2 . The mean change from 1986 to 1991 and 1992 to1998 was an increase of 0.5 . Although the change is minimal, this research shows that the recent gastric cancer mortality rate is on the rise. If in fact gastric cancer mortality is linked to race or ethnicity, the change could be the result of an 
increasing Hispanic population in Texas. This could also be related to poor diets low in fruits and vegetables and high in smoked, salted, and processed food. In short, as gastric cancer mortality increases, further research is needed to fully understand the disease.

\section{Conclusion}

Gastric cancer mortality rates were positively related to Hispanic and urban population, but negatively related to White and rural populations in the county. Also, gastric cancer mortality in Texas is higher in males than in females. This could be related to the fact that women generally have better health habits than men (Lonnquist \& Weiss, 2006). It is also important to note that, while median income and gastric cancer mortality did not have a significant relationship across the state as a whole, it was found that the percentage of White population had a positive relationship with median income, and the percentage of Hispanic population had a negative relationship with median income. This is important because it appears that when median income is assessed among race/ethnicity groups, socioeconomic status does play a role in gastric cancer mortality. Another point of interest is that when areas with high nitrate groundwater concentration and high gastric cancer mortality were investigated, they were also found to have a high percentage of the population engaged in mining. Lastly, with gastric cancer mortality on the rise, it is important that further research be done in order to identify other possible risk factors and risk markers.

\section{Limitations of Research}

Although careful measures were taken in this research in order to ensure accuracy, there are limitations. One limitation of this research is that the percentage of groundwater usage per county was not taken into account because these data were unavailable at the time of data collection. Another limitation is that the latency of gastric cancer was unaccounted for, in that 
this research was not based on an individual level, but on the Texas population as a whole.

Lastly, the ever-increasing mobility of people was not accounted for because, again, this research was not based on the individual level, but on Texas as a whole. 


\section{References}

Anderson, A., Hǿgsaet, B., Langård, S., and Zandjani, F. (1994). Incidence of cancer among nitrate fertilizer workers. International Archives of Occupational and Environmental Health, 66(3): 189-193.

Burbano, L. C., Correa, P., Cuello, C., Duque, E., and Garcia, F. T. (1976). Gastric cancer in Columbia. National Cancer Institute, 57(5): 1015-1020.

Cerhan, B. C., Hallberg, J. K., Kross, G. R., and Weyer, P. (2001). Municipal drinking water nitrate level and cancer risk in older women: The Iowa women's health study. Epidemiology, 12(3): 327-338.

Cheng, M., Hsieh, Y., Tsai, S., and Yang, C. (1998). Calcium, magnesium, and nitrate in drinking water and gastric cancer mortality. Cancer Science, 89(2): 124-130.

Doll, R. (2006). Urban and Rural Factors in the Aetiology of Cancer. International Journal of Cancer, 47(5): 803-810.

Environmental Protection Agency. (n.d.). Nitrates/Nitrites. Retrieved on September 15, 2007, from http://www.epa.gov/safewater/contaminants/dw_contamfs/nitrates.html.

Gastric Cancer Facts. (n.d.). What is Gastric Cancer? Retrieved on September 3, 2007, from http://www.gastriccancerfacts.org/.

Harvard Center for Cancer Prevention. (n.d.). Stomach Cancer: Risk Factors. Retrieved on September 23, 2007, from http://www.hsph.harvard.edu/cancer/cancers/stomach/riskfactors/index.htm.

Jemal, A., Siegel, R., Ward, E., Murray, T., Xu, J., Smigal, C., and Thun, M. J. (2006). Cancer statistics, 2006. CA: A Cancer Journal for Clinicians, 56(2): 106-130.

Lonnquist, L., and Weiss, G. (2006). The Sociology of Health, Healing, and Illness (5 ${ }^{\text {th }}$ ed.). New Jersey: Prentice Hall.

National Cancer Institute. (n.d.). Gastric Cancer Treatment. Retrieved on September 4, 2007 , from http://www.cancer.gov/cancertopics/pdq/treatment/gastric/healthprofessional/.

O’Brien, K., Cokkinides, V., Jemal, A., Cardinez, C. J., Murray, T., Samuels, A., Ward, E., and Thun, M. J. (2003). Cancer statistics for Hispanics, 2003. CA: A Cancer Journal for Clinicians, 53(4): 203-226.

Potter, J., and Steinmetz, K. (1991). Vegetables, fruit, and cancer. Cancer Causes and Control, 2(6): 427-442.

Roder, D. (2002). The epidemiology of gastric cancer. Gastric Cancer Journal, 5. 
Texas Water Development Board. (n.d.). Groundwater Database Downloads. Retrieved on October 27, 2007, from http://www.twdb.state.tx.us/publications/reports/GroundWaterReports/GWDatabaseRepo rts/GWdatabaserpt.htm. 
Figure 1. Texas Map Showing Age-Adjusted Death Rate by County due to Gastric Cancers from 1980-1998

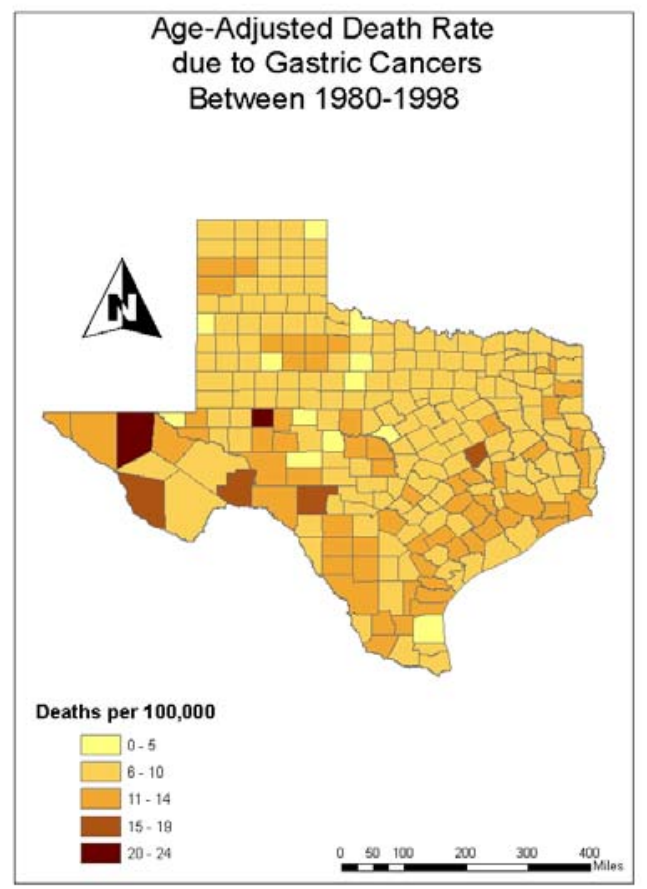


Figure 2. Texas Map Showing Percent White Population by County

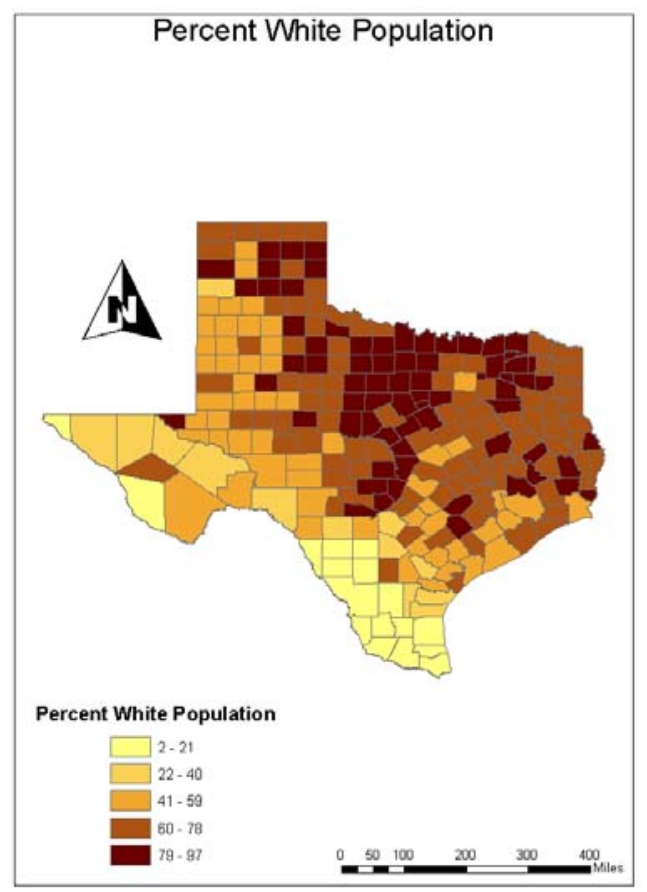


Figure 3. Texas Map Showing Percent Hispanic Population by County

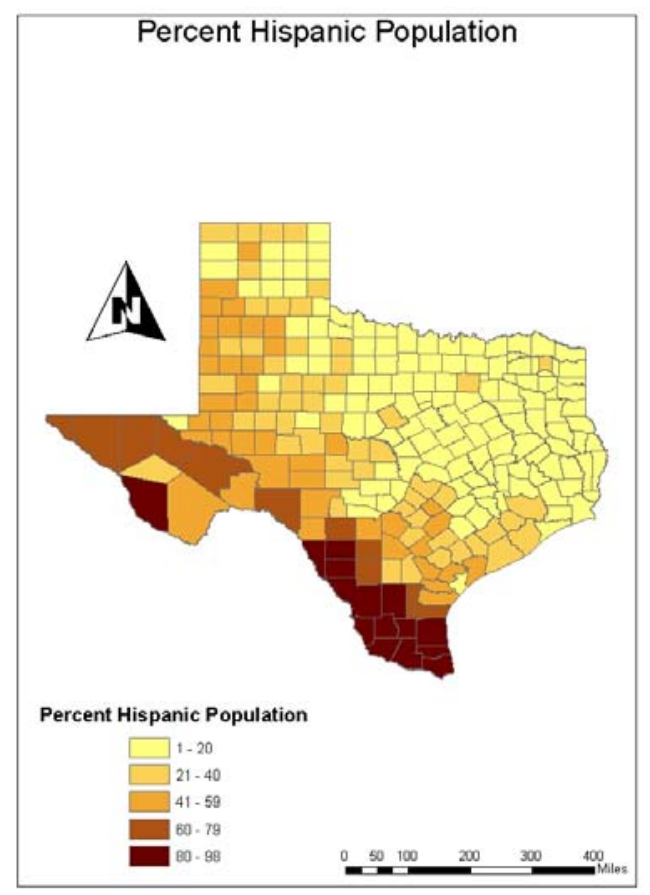


Figure 4. Texas Map Showing Percent Population Involved in Agriculture by County

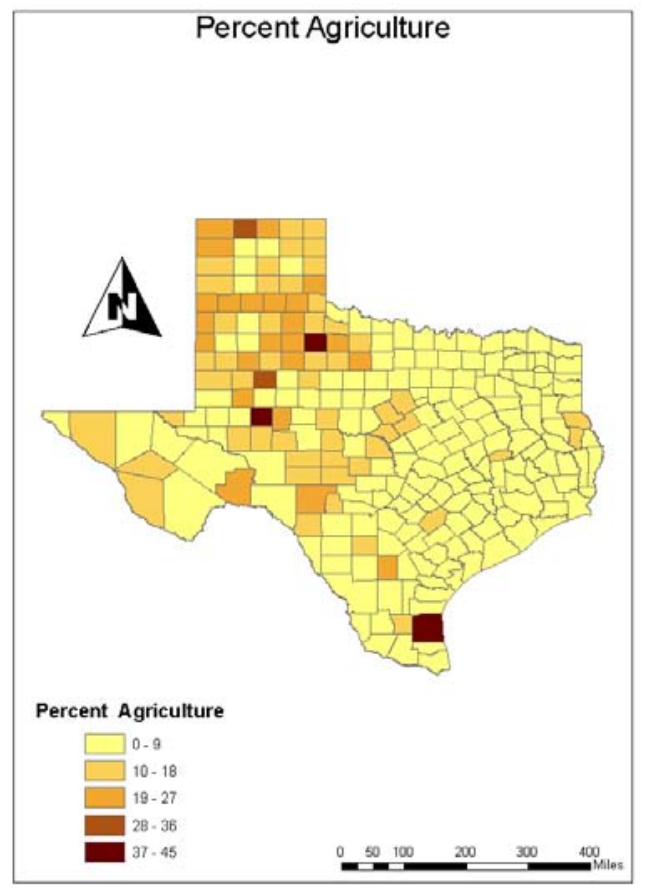


Figure 5. Texas Map Showing Percent Population Involved in Mining by County

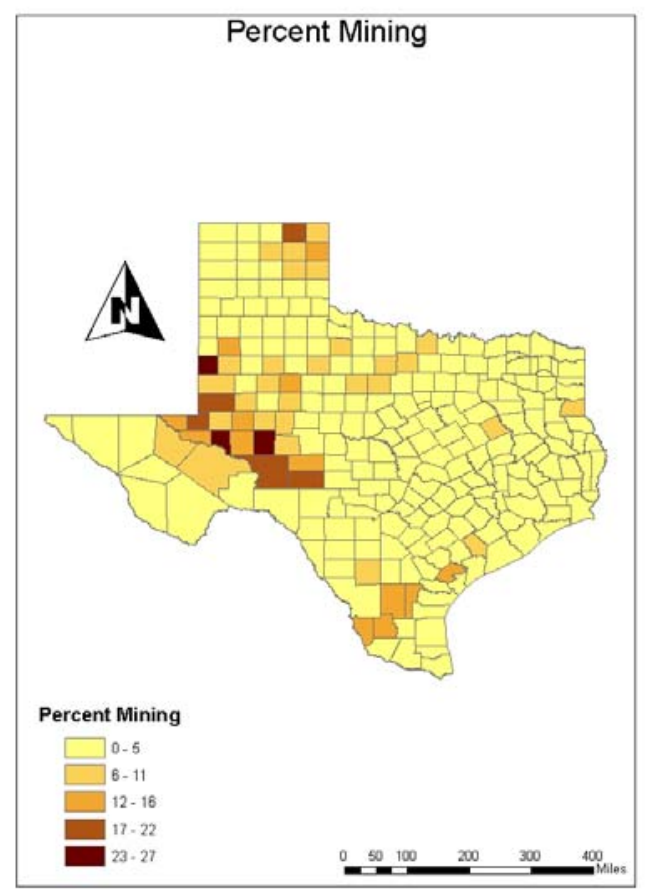


Figure 6. Texas Map Showing Percent Urban Population by County

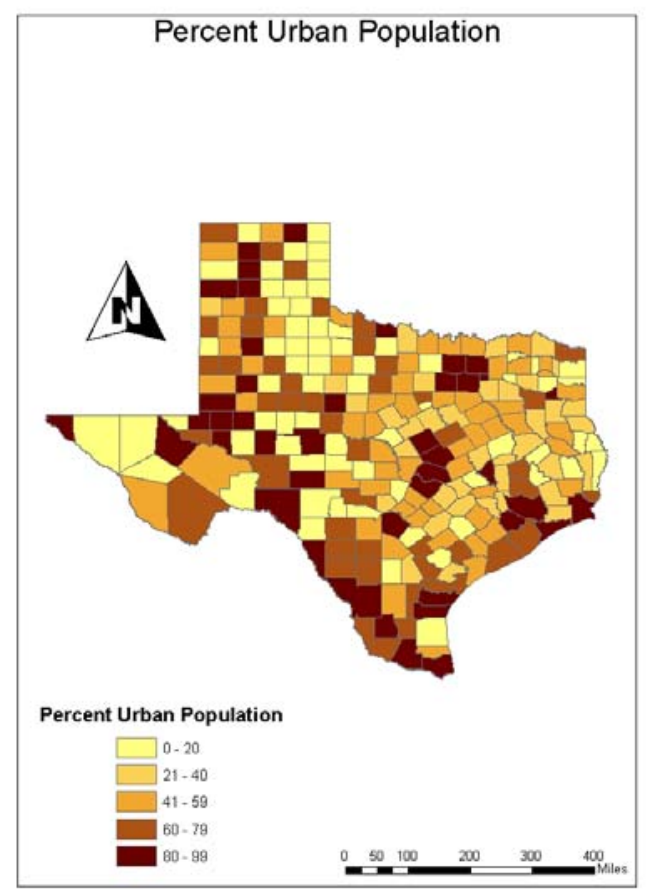


Figure 7. Texas Map Showing Nitrate Concentration Levels and Age-Adjusted Death Rate by County

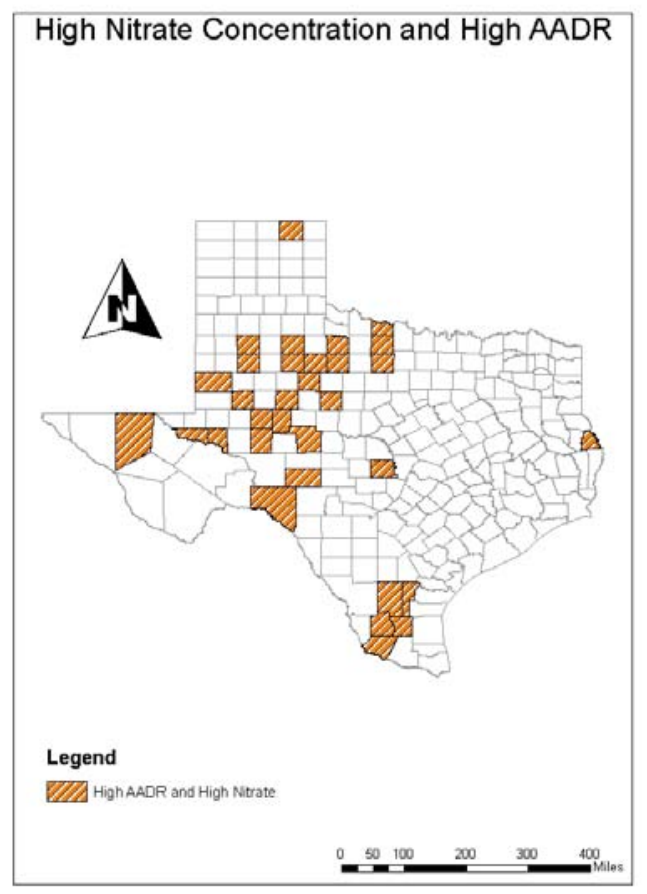

